https://doi.org/10.46344/JBINO.2020.v09i03.09

\title{
ENOXAPARIN FOR DEEP VENOUS THROMBOEMBOLISM (DVT)- REVIEW ARTICLE
}

\section{Em Sutrisna}

\author{
Medical Faculty of Universitas Muhammadiyah Surakarta
}

Email Id: es233@ums.ac.id

\begin{abstract}
Deep vein thrombosis is thrombus formation in deep vein that dominantly occurring in lower limb and pelvis. Enoxaparin is a low molecular weight heparin that has been used widely. The aim of this review is to get evidence base of DVT treatment by enoxaparin. Study was done by search in Pub med with keywords Enoxaparin and DVT and were found 6 articles. Search by data base Science direct with keywords enoxaparin and were found 98 articles. Of these, we only use 32 articles related to this discussion. The results of this study are enoxaparin can used to phropilaxy of DVT on patients undergoing surgery especially hip or knee arthroplasty. Enoxaparin still effective to treat DVT.
\end{abstract}

Keywords: Enoxaparin, DVT, Pubmed, Science direct

No: of References: 32 


\section{INTRODUCTION}

Deep vein thrombosis (DVT), is a major cause of morbidity and mortality worldwide that prevented. This diseases was caused by thrombus formation in deep vein. Most location of DVT is pelvis and lower limb (1). The estimated DVT incidence is $2 / 3$ of the total VTE and it is estimated to occur 1 per 1,000 people each year (2-4). About 1/3 of DVT cases can develop pulmonary embolism (PE) (5).Venous thrombosis is thrombosis in deep vein that caused by coagulation blood flow in stasis vein. (6-8). Around $10 \%$ in patients suffer DVT was cared in ICU (9). The clinical symptoms of DVT varies depending on the area and location of the thrombus. The cardinal signs and symptoms of DVT are asymmetrical swelling, warmth, or pain in the extremities (10). Suspected Patients DVT was checked D-dimer. The D-dimer level $<0.5 \mathrm{mg} / \mathrm{mL}$ was not DVT. D-dimer level is sensitive but lack of spesivity (11-12). The Gold standard diagnosis is Angiografi and USG USG doppler

\section{TREATMENT bY ENOXAPARIN}

The goal of DVT treatment is to prevent thrombus formation or spreading of thrombus, preventing pulmonary embolism, and post thrombotic syndrome. The combination Heparin and oral anticoagulan oral are the choose initial treatment $(7,13)$.

Enoxaparin is a low molecular weight heparin anticoagulant. This drug was prepared by alkaline degradation of unfractionated benzylated heparin intestinal mucosa of porcine (14-16). This medicine is indicated to Prophylaxis and treatment of thromboembolism in children; management of venous thromboembolism on pregnancy; anticoagulant therapy during temporary interruption of vitamin $\mathrm{K}$ antagonist therapy in patients at high risk for thromboembolism; prophylaxis of DVT following moderate-risk general surgery; major gynecologic surgery and Prophylaxis following higher-risk general surgery for cancer (17).

This medicine act like as unfractionated heparin. Enoxaparin bound anti-thrombin resulting inactivation of $\mathrm{Xa}$ factor. The adverse event (bleeding and thrombocytopenia) of low molecular weight heparin lower than unfractionated heparin. Research by Zenáhlíková et al., 2010 found that in most patients with sepsis, prophylaxis with enoxaparin did not cause the necessary FXa inhibition. Inhibition of FXa by enoxaparin depends mainly anti thrombin and protein C activity (18). Enoxaparin (40mg subcutaneous daily for 2 weeks) as a low molecular weight heparin effective as prophylaxis against thromboembolism following total knee replacement surgery (19). Enoxaparin prophylactic at dose of 30-mg twice-daily is inadequate in many burn patients to prevent developing deep venous thrombosis (DVT) (20).

A meta-analysis by Patrick et al, found that the observed RR (enoxaparin/UFH) of VTE patients with DVT was $0.81195 \% \mathrm{Cl}, 0.52-$ 1.26) for the intention-to-treat population (RR, 0.70; 95\% Cl, 0.43-1.13; for per-protocol analysis) (21). Research by Steven et al, 
2000 that involved 263 patients who underwent total knee arthroplasty, 122 received adjusted low-dose warfarin and 141 received enoxaparin as deep vein thrombosis (DVT) prophylaxis. Three patients in the warfarin group and 3 in the enoxaparin group developed ultrasounddetectable DVT $(P>$.05). From the results, can be concluded that enoxaparin reduced DVT incidence (22).

Borris et al. compared use of enoxaparin with dextran 70 as a prophylaxis thrombosis in patients underwent hip arthroplasty. There were 206 consecutive patients underwent hip arthroplasty during thromboprophylaxis involved in this research. A total 6 of $102(6 \%)$ treated by enoxaparin developed deep vein thrombosis (DVT), meanwhile 21 of 104 $(20 \%)$ in dextran group patients (23).

The once-daily enoxaparin at dose of 1.5 $\mathrm{mg} / \mathrm{kg}$ subcutaneously has the same effectiveness and safety as conventional treatment with continuous intravenous UFH infusion. However, once-daily enoxaparin regimens are easier to administer (subcutaneously vs intravenously), do not require monitoring of aPT, and reduce the average hospital stay 4 days shorter (24).

Efficacy of enoxaparin higher than new drug dabigatran at dose of $150 \mathrm{mg}$, and adverse effect of bleeding from enoxaparin lower than fondaparinux (25). Research by Norwood et al, 2001, that covered 118 patients blunt trauma found that enoxaparin prevent venous thromboembolism in this patients. Only $2 \%$ patient developed DVT with one of which was proximal to the calf $(95 \% \mathrm{Cl}, 0 \%-6 \%)$ (26).A prospective study that designed in which 165 patients with symptomatic, unilateral, first-episode DVT were done by José A.González-Fajardo. The design wass randomized to a long-term anticoagulant treatment with coumarin or enoxaparin during at least 3 months. The results of this research were: the enoxaparin group have lesser incidence of Postthrombotic syndrome (39.3\% absent, $19.6 \%$ severe) compare by coumarin group. (29.5\% absent, $29.5 \%$ severe). The accumulated recurrence rate of enoxaparin lower than coumarin $(19.3 \%$ vs $36.6 \%$ with $(P=.02)$ (27).

Clinical Research with animal studies (dogs) by Mooris et al, concluded that enoxaparin (100 units $/ \mathrm{kg}(1.0 \mathrm{mg} / \mathrm{kg})$ every 12 hours) inhibited propagation of preformed thrombi as effective as dalteparin ( $(200$ units/kg every 24 hours $(n=4))(28)$.

Research by Riha et al, involved 63 patients $(28$ patients were treated by enoxaparin on $30 \mathrm{mg}$ twice daily, 35 patients on $40 \mathrm{mg}$ once daily). The results of this research were the incidence of DVT in surgical patients who receive $30 \mathrm{mg}$ twice daily higher than $40 \mathrm{mg}$ daily. Enoxaparin at dose of $40 \mathrm{mg}$ per day results peak anti-Xa levels higher than 30 mg twice daily significantly (29).

Enoxaparin has affectivities in prevention of VTE after total knee replacement lower than rivaroxaban and apixaban (direct $\mathrm{Xa}$ inhibitors) (30). Research by Kurtoglu, et al, 2010, involved 246 patients (128 men with 
mean age, $54.28 \pm 16.48$ vs 118 women with mean age, $50.11 \pm 16.47$ years old) with symptomatic lower extremity DVT. All patients were included in this open-label, single-arm, multicenter, phase IV clinical trial conducted at 14 centers in Turkey. The research resulted enoxaparin plus warfarin reduced physical symptoms, including tenderness, edema, pain $(P<.001)$, and the circumference of the affected leg $(P<$ $.001)$. Enoxaparin plus warfarin is effective in improving clinical symptoms by reducing thrombus formation without a significant risk of major bleeding for the outpatient ambulatory treatment of lower-limb deep vein thrombosis (31).

Research by Nurmohamed et al., 1995 involved 1427 patient's postoperative deep vein thrombosis in general surgery. The results were: DVT was detected in 58 enoxaparin-treated patients $18.1 \%, 95 \% ; \mathrm{Cl}$ $6.2 \%-10.3 \%$ ) and in 45 patients treated by heparin $(6.3 \%, 95 \% \mathrm{Cl} 4.7 \%-8.4 \%, P>0.05)$. Major bleeding complications occurred in 11 patients treated by enoxaparin $1.5 \%$, $95 \% \mathrm{Cl} 0.8 \%-2.7 \%)$ and in 18 patients treated by heparin $(2.5 \%, 95 \% \mathrm{Cl} 1.5 \%$ $3.9 \%, P>0.05)$. A total Four patients treated by enoxaparin $(0.6 \%)$ required reoperation for bleeding as compared to 13 patients in heparin group $(1.8 \%, P=0.03)$. Enoxaparin (low molecular weight heparin) showed as effective and safe as Heparin (32)

\section{CONCLUSION}

Enoxaparin is low molecular weight heparin. This medicine effective to reduce DVT incidence on patients undergoing surgery. Enoxaparin still effective to treat DVT with minor adverse event.

\section{REFERENCES}

1. Caldeira D, Rodrigues FB, Barra $M$, Santos AT, de Abreu D, Gonçalves N, Pinto FJ, Ferreira JJ, Costa J. Nonvitamin $\mathrm{K}$ antagonist oral anticoagulants and major bleedingrelated fatality in patients with atrial fibrillation and venous thromboembolism: a systematic review and meta-analysis. Heart 2015; 101: 1204-1211

2. Beckman MG, Hooper WC, Critchley SE, et al. Venous thromboembolism: a public health concern. Am J Prev Med, 2010;38:S495-501.

3. White RH. The epidemiology of venous thrombo embolism. Circulation 2003;107:14-8.

4. Silverstein MD, Heit JA, Mohr DN, et al. Trends in the incidence of deep vein thrombosis and pulmonary embolism: a 25-year populationbased study. Arch Intern Med 1998;158:585-93.

5. Kearon C. Natural history of venous thromboembolism. Circulation 2003;1 07:122-30.

6. Qaseem A,Snow V,Barry P,Hornbake ER RodnickJE, Tobolict, et al. 2007, Current diagnosis of venous thromboembolism in primary care:a clinical practice guideline from the American Academy of Family Physician and the American College of Physicians. Ann Fam Med, ; 5(1):57-62

7. ScarvelisD \& Wells P. Diagnosis and Treatment of deep-vein thrombosis. CMAJ, $2006 ; 175(9): 1087-1092$ 
8. Kelly J, Rudd A, Lewis RR, Hunt BJ. Plasma D-dimers in the diagnosis of venous thromboembolism. Arch Intern Med 2002;162:747-56.

9. Kahn SR. 2006, Frequency and determinants of the post thrombotic syndrome after venous thromboembolism. Curt Opin Pulm Med, 12:299-303

10. Wells PS, Anderson DR, Bormanis J, et al. Value of assessment of pretest probability of deep-vein thrombosis in clinical management . Lancet 1997;350:1795-8.

11. Adam S, Key N, Greenberg C, 2009. D-dimer antigen: current concepts and future prospects.Blood, 113:2878-87

12. Wolberg A, Mackman N, Venous thromboembolism: risk factors, biomarkers, and treatment. Arterioscler Thromb Vasc Biol, 2009, 29:296-297

13. Key NS, Kasthuri RS. Current treatment of venous thrombo embolism. Arterioscler Thromb Vasc Biol, 30: 372-375

14. Buckley MM, Sorkin EM. Enoxaparin: A review of its pharmacology and clinical applications in the prevention and treatment of thromboembolic disorders. Drugs. 1992; 44:465-97.

15. Turpie A. Enoxaparin prophylaxis in elective hip surgery. Acta Chir Scand Suppl. 1990; 556:103-107.

16. Fareed J, Walenga JM, Lassen $M$ et al. Pharmacologic profile of a low molecular weight heparin (enoxaparin): experimental and clinical validation of the prophylactic antithrombotic effects. Acta Chir Scand Suppl. 1990; 556:7590.

17. Hirsh J, Dalen J, and Guyatt G, et al, The Sixth (2000) ACCP Guidelines for Antithrombotic Therapy for Prevention and Treatment of Thrombosis. American College of Chest Physicians, Chest, 2001, 119(1 Suppl):346-7

18.Zenáhlíková , Kvasnicka J, Kudrnová Z, Sudrová M, Brzezková R, Mazoch J, Malíková I, Vyborny J, Erhart D, Pecen L ,FXa inhibition and coagulation changes during DVT prophylaxis

by enoxaparin over the course of a 15-day follow-up in septic patients. Clin Appl Thromb Hemost. 2010 ;16(5):584-90

19. Niazi AU, Umer $M$, Umar $M$, Prophylaxis of DVT with enoxaparin in patients undergoing total knee replacement. J Pak Med Assoc. 2006 Feb;56(2):72-5.

20. Cronin BJ , Godat LN, .Berndtson AE, Pham A, Kolan S, Box K, Lee JG, Costantini TW, Anti-Xa guided enoxaparin dose adjustment improves pharmacologic deep venous thrombosis prophylaxis in burn patients, Burns, 2019, 45(4): 818824

21.PatrickM, Sara Q, Mark L, Geno M, Hervé D, Silvy L., Enoxaparin in the Treatment of Deep Vein Thrombosis With or Without Pulmonary Embolism: An Individual Patient Data Metaanalysis, Clinical Investigations, 2005, 128(4): 2203-2210 
22. Steven H.Stern Richard L.Wixson MD Daryl O'Connor, Evaluation of the safety and efficacy of enoxaparin and warfarin for prevention of deep vein thrombosis after total knee arthroplasty, The Journal of Arthroplasty, 2000, 15(2): 153-158

23. Borris, LC, Sørensen JV, Lassen MR, Walenga JM, Fareed J, Jørgensen LN, Hauch O, PeerWille-Jørgensen, Components of coagulation and fibrinolysis during thrombosis prophylaxis with a low molecular weight heparin (Enoxaparin) versus Dextran 70 in hip arthroplasty, Thrombosis Research, 63 (1): 21-28

24. Ramacciotti E, Araújo GR, Lastoria $S$, Maffei FHA, de Moura LK, Michaelis W, Sandri JS, Neto FD, An open-label, comparative study of the efficacy and safety of once-daily dose of enoxaparin versus unfractionated heparin in the treatment of proximal lower limb deep-vein thrombosis, Thrombosis Research,2004, 114(3): 149-153

25. Alvarenga Rd, Bonetti YW, Francisco $\mathrm{Y}$, de Abreu H, MaffeiRegina, El DibRogério, Hamilton N, AlmeidaRollo, Systematic Review of Randomized Controlled Trials of New Anticoagulants for Venous Thromboembolism Prophylaxis in Major Orthopedic Surgeries, Compared With Enoxaparin, Annals of Vascular Surgery, 2013, 27(3): 355369

26. Norwood SH, Auley CE, Berne JD, Vallina VL, Kerns DB, Grahm TW, McLarty JW, A potentially expanded role for enoxaparin in preventing venous thromboembolism in high risk blunt trauma patient, Journal of the American College of Surgeons, 2001, 192(2): 161-167

27. González-Fajardo JA， MartinPedrosaM, CastrodezaJ, Tamames $S$, CarlosVaquero-Puerta, , Effect of the anticoagulant therapy in the incidence of post-thrombotic syndrome and recurrent thromboembolism: Comparative study of enoxaparin versus coumarin, Journal of Vascular Surgery,2008, 48(4): 953-959.e2

28. Morris TA, Marsh JJ, RonaldKonopka, Craig APedersen, Peter GChiles, Anti-thrombotic Efficacies of Enoxaparin, Dalteparin, and Unfractionated Heparin inVenous Thrombo-embolism,

29. Riha GM., Van PY. Differding JA, Schreiber MA, Incidence of deep vein thrombosis is increased with 30 mg twice daily dosing of enoxaparin compared with $40 \mathrm{mg}$ daily, The American Journal of Surgery, 2012, 203(5): 598-602.

30.Guofeng Ma, Ruifeng Zhang, XiaohongWu, DanWang, KejingYing, Direct factor $\mathrm{Xa}$ inhibitors (rivaroxaban and apixaban) versus enoxaparin for the prevention of venous thromboembolism after total knee replacement: A meta-analysis of 6 randomized clinical trials, Thrombosis Research, 2015, 135(5): 816-822

31.Kurtoglu, $M$, CuneytKoksoy, Hasan E, Akcalı Y, Long-term efficacy and safety of once-daily enoxaparin plus warfarin for the outpatient | Innovative Association 
ambulatory treatment of lower-limb deep vein thrombosis, Journal of Vascular Surgery, 2010, 52(5): 12621270

32. Nurmohamed, MT, Verhaeghe, R, Haas S, Iriatte JA, Vogel G, Andre M.van Rij Prentice CRM, Jan W.ten Cate, A comparative trial of a low molecular weight heparin (enoxaparin) versus standard heparin for the prophylaxis of postoperative deep vein thrombosis in general surgery, The American Journal of Surgery, 1995, 169 (6): 567571 